Beyond 'A Trip to the Seaside': Exploring Emotions and Family Tourism Experiences. 


\title{
Beyond 'A Trip to the Seaside': Exploring Emotions and Family Tourism Experiences
}

\begin{abstract}
Family tourism is a key tourism segment, yet it is often taken for granted, and therefore passed over in contemporary research studies. Little research exists in the tourism literature that explores the experiential aspect of how families perform tourism in various spatial settings. Furthermore, the emotional aspects of such family tourism performances receive little attention. The concepts of existential authenticity and of 'interpersonal authenticity' are used to assess how families construct ideals of 'their real' (collective) selves, while on holiday at the beach, together. A case study of Brighton in the UK assesses family holiday experiences in a traditional British seaside resort. The primary research findings show that emotional connections are strengthened during family coastal holidays. These connections are not without complexity and contestation, particularly in terms of intra-family power relationships, gender and the social reproduction of domestic/holiday roles. The concept of quality time is revealed as a varied but important value in family tourism motivations. Wellbeing improvements (emotional, physical and psycho-social) are reported widely across the sample. The creation of memorable tourism experiences is shown to be a key driver for families as they attempt to come together away from the busyness of everyday stresses. Human-seascape interactions form a meaningful socio-spatial context for these explorations. The sea space itself facilitates the myriad of idealised expectations around family holiday connections. Deeper insights are therefore offered into a key tourism offering, 'the family holiday', through a lens that is often overlooked.
\end{abstract}

Keywords: family-tourism, memorable-tourism-experiences, family holidays, coast, existentialauthenticity, interpersonal-authenticity, emotions, wellbeing, sea, quality-time 


\section{Introduction}

This article seeks to contribute to touristic spatialities of emotion, specifically through the locus of the coastal environment, and via the lens of 'the family'. The role of emotions has until recently (e.g. Pritchard et al, 2011, Kearns and Collins, 2012, Buda et al, 2014, d'Hauteserre, 2015, Servidio and Ruffalo, 2016), been relatively overlooked in the field of tourism studies. This paper seeks to redress the role of emotions and touch on corporeality (or embodied feelings) in often taken-for-granted family tourism encounters and tourism spaces. The sea, the coast and the beach are key loci for tourism performances and tourism experiences. Affective forces of encounter at the sea involve sensory engagement with sight, smell, touch, and emotion. The affective atunement between human and the non-human physical elements of the beach, the coastal space and indeed the water itself have yet to be sufficiently explored by researchers within tourism studies. All arguably contribute to memorable tourism experiences, where families connect emotionally in specific ways, temporarily, in coastal spaces. This work explores some of these connections, how they are often constructed as more authentic than everyday experiences, and questions the role of the coastal setting itself.

This research has two central objectives - (i) to analyse the differential nature of emotional connections and experiences in family coastal tourism using a UK case study approach; and (ii) to discuss existential and interpersonal authenticity as forms of psycho-social family tourism outcomes. Adjunct explorations consider how the above contribute to 'memorable tourism experiences', as perceived and constructed by families on holiday at the coast. The paper also discusses the role the coast itself plays in family tourism experiences and emotions. 
This research argues that the coast itself can be more closely examined to deconstruct specific spatialities that are valued and that elicit certain responses. The paper explores the family-emotion-identity nexus as it plays out through and is shaped by the sea. The family is chosen as a unit of tourism study to assess the importance of memorable tourism experiences and their associated emotional expectations, connections and realities. Notions of existential, or 'real family authenticity' are unpacked as we discover what being on holiday can do to temporarily transform, or emotionally ameliorate everyday busy-life realities. The coast in contemporary leisure societies is often constructed as a place of strong emotional meaning, and families often perceive this place (taken here to mean coastal landscapes, the beach and the water itself) as a space for freedom, fun, escape, expressions of childhood, bonding and constructs of authentic familial connection.

The sensory material reality of the biophysical world of the coast actively contributes to the symbolic value of the coast in constructing family stories, as well as offering emotional connectivity in itself. Watching the sea come into view at the end of a long car or plane journey, feeling the sand beneath bare feet, smelling the salty air, allowing the shoulders to relax, water touching skin and hearing the sound of the waves all elicit an emotional sensory response that is, arguably, the essence of many coastal tourism experiences.

In the next section, this paper will review literature related to the themes outlined in the paper's objectives - i.e. emotions and family tourism, existential and interpersonal authenticity, as well as ideas around memorable tourism experiences, and 
the role of the coast/sea as a space for performing (family) tourism. Thereafter, a conceptual framework is presented using some of the concepts above. A methodology section then presents a case study of one British seaside resort, Brighton, on England's south coast, using sixty interviews from sample families on or near the beach. A qualitative analysis of the research findings follows, where a thematic analysis of interviews and observations is presented. A final discussion and conclusion draw together key outcomes and suggestions for future research directions in family coastal tourism geographies.

\section{Emotions and Family Tourism}

Tourism research has presented family tourism mainly in terms of taken-forgranted market analysis, package tourism preferences and decision making (Minnaert and Jens, 2017). Little, however, has been said about the emotional aspects of the need for holidays as forms of family respite, nor the emotional investment that is involved symbolically, and psychologically. Scope exists therefore to delve into the feelings that create the perceived need for a holiday. These can be explored in terms of the anticipatory emotions leading up to the trip, those felt while on the holiday itself, and those reflective feelings post-trip, that in turn become memorable tourism experiences. These are complex, multifaceted and difficult issues to deconstruct - particularly across cultures, time, gender and space. It is acknowledged that humans are also not passive recipients of emotions. Given the challenges of this subject matter, the emotional affect of many elements of family holidays is often not explicitly extracted from tourism studies. 
The relationship between families and emotions are usually private, internal interplays in the realm of the home- yet the arena of tourism allows for some of these to be considered and overtly displayed in public spaces, such as the beach. Indeed, Obrador (2012) notes that one reason for the invisibility of the family in tourism studies is the very notion that the family's place is mainly the home, which is contrary to the dominant focus of tourism investigation. This research will examine some of the experiences, emotions, performances and affect of family holidays, with the sea/coast/water as a repository co-agent for such expressions.

Tourism studies have often taken the notion of family for granted. It is seen as a key 'market segment', but there is much more scope for exploring how families organise themselves, behave, perform emotions, and construct memorable tourism experiences according to their own self-identities and values. These identities may be complex and internally fractious. The mix of gender, children's ages and internal parental power relations can result in very different experiences both between family members and across different family markets/cultures

The family can be viewed as a form of social group, one held together by a common purpose, and one that is different to other types of groups in society. Day, Gilbert, Settles and Burr (1995) argue that family members may be more intensely bonded through emotional ties, and that there is often a shared family paradigm or world view. Although larger constructs are useful for understanding the family, they do not specifically define any one family. There is further scope in tourism studies to correlate self-constructs of family paradigms to tourism behaviours - families who selfidentify as 'the adventurous family, 'the cultural family, 'the fun family' and so on... 
Constructs of 'the family' are dynamic and changing as societal structures become more fluid. Modern families range from heteronormative 2.4 children formats, to same sex parents with children, single parent families, blended families with children from multiple marriages and a spectrum of high-to-low levels of extended familial support. From an economic perspective, it is one of the fastest growing and most consistent tourism markets, with $80 \%$ of respondents in a 2017 industry survey citing 'quality family/children time' as a key motivation to travel (Shaw, 2010, Schanzel and Yeoman, 2014). Quality time in itself, is a contested term. Snyder's (2007) research on how parents themselves defined or constructed quality time showed differential results. She classified quality time into 3 categories, based on her research; 'structured planning', 'child-centred', and 'time available'. For this paper, structured-planning parents are key. They define quality time as 'time specifically set aside from normal daily routines for special family activities, such as a vacation' (p.327). This idea of quality time, particularly in terms of holiday making, has become part of our cultural discourse, and is for some, synonymous with what it means to be 'a good parent', or indeed, 'a happy family'. This becomes evident in the findings section of this paper.

Such quality time however, may be fraught with complex expectations, gendered holiday/domestic labour performances and unrealistic projected ideals of delineated time and space. Obrador (2012) explores how homely feelings and idealizations of the family are formed and performed on holiday, noting that family holiday processes can highlight the importance of tourism in the reproduction of social networks and relations of domesticity. Gender and power relationships around social reproductive roles are something that also require more attention overall in family tourism studies. Mothers may often be the ones who influence the choice of holiday type, and may do the majority of menial tasks of laundry, packing, cleaning and cooking 
both at home and on (particularly self-catering) holiday. Therefore, family holidays are experienced differentially within a family unit in terms of relaxation and chores undertaken. The findings in this work later, show that this is a complex issue in many families.

Everyday realities for modern families are often fraught with multi-tasking working parents, commuting, childcare logistics, and juggling school-age children's activities, homework and caring challenges. Weekends are often busy for families, so there may not be much opportunity for proper downtime beyond designated vacation/holiday periods. Because of this, the role of the family holiday becomes loaded with expectation and projected constructs of what it means 'to be a family', to relax together, to bond and to enjoy time away from 'normal life' stressors. Family tourism interestingly allows for the intertwined relationships of affect with everydayness to be considered. We may feel threatened in not having something that constructs our existence, because we feel undefined with its absence (Greg and Seigworth, 2010), which may partially help to explain the notion of not feeling like 'a real family', without going on a 'proper family holiday'. Affective tourism approaches give further opportunities to explore such internal drives (Buda, 2015).

Family tourists are also, as Obrador-Pons (2003) notes, situated and embodied subjects whose lives unfold in reciprocal interactions with their environment. Notions of affect, emotions and feelings between humans in the family unit, and the coastal space itself plays an important role in deeper understandings of this tourism segment. Families can create affective resonance, among themselves and with the sea, where we accept the affective premise of a lack of distinction between person and environment (Gregg and Seigworth, 2010; Massumi, 2015). Questions can be posed therefore about how the 
coast acts as a repository for/facilitates manifestations of emotion and familial authenticity.

\section{Existential and Inter-Personal Authenticity}

Authenticity is an important notion, and it is closely related to the ability to express our true emotions (Belhasson and Caton, 2006). The concept of authenticity however, is socially constructed. It is not an objective quality of a thing, place or experience, but rather, a discourse through which certain practices (or objects) are made meaningful through a socially constructed system. One of the most common sources of anxiety, malcontent and stress in contemporary society is the feeling of not being able to live our life with purpose, the life we really want (or have constructed in our minds as reflective of who we are/our values), engaging in daily activities, work or connections that allow us to be our 'real selves'. Sociologists would argue that there is no such thing as a real or authentic self - that the self is a social construct and the effect of social performances (Goffman, 1990). However, there is merit in thinking about this as a personal construct, in so far as many tourists have indeed emphasised this idea of "just being free to be myself on holiday' (see findings later in this paper).

The concept of expressing authentic self-identity (existential authenticity) through holiday destination or activity choices has been presented by some tourism researchers (Wang, 1999, Kirillova and Lehto, 2015). However, challenges still remain conceptually, to understand why the 'holiday self' might be seen or experienced by some tourists as more 'real' than an everyday/work/parent self. Perhaps the answers lie in the removal of stress (deadlines, commuting, parenting) and/or the mundanity of repetitive work or domestic tasks. The idea of not having to perform our professional roles, work to schedules, or perform emotional labour - when on holiday may lead to an 
improvement in personal wellbeing for some. Others may struggle to let go of their professional personas, or to unwind sufficiently without structure. For some tourists, escape from everyday pressures may result in the hedonistic behaviours of release or excess, often associated with mass tourism. Therefore, there is potential for 'differential versions of the self' to be performed in different contexts and almost certainly in different holiday contexts, settings and groupings. Existential authenticity, or feelings of really being oneself, are therefore complex and problematic in essence.

Individual senses of existential authenticity are socially constructed across gender, culture, age, life experiences, education, personal awareness and reflexivity. When this is examined at the level of the family unit however, the concept of 'interpersonal authenticity' is important. Kim and Jamal (2007) propose the idea InterPersonal Authenticity (IPA) which examines emotional bonds, intimacy in family relationships and the pleasure derived from such human connections. Let us consider the varied opportunities for this in everyday life versus holiday time. Collectively, families often suffer from a dearth of everyday quality time (Synder, 2007) where parents and children are physically present and even temporarily, emotionally connected through a common sense of purpose or engagement. Therefore, in addition to seeking idealised locations for family holidays, there is the added emotional need for collective bonding, and the desire 'to feel like a proper family', or to perform roles such as the 'good wife', or the 'attentive husband', 'the present father', or 'the loving child'. In other words, an opportunity to perform better versions of ourselves. These notions of idealized holiday spaces and family roles or performances are socially determined, through external forces such as the media, marketing imagery and even peer behaviours. The problematics of idealized constructs of (our)selves, and ourselves as families, as we perform certain holiday roles are complex but interesting considerations. 


\section{The Coast and Family Emotional Wellbeing}

Here, we can assess how the coast may be constructed as an idealized psychosocial space for the emotions of release, restfulness, bonding and escapism by parents. In their study of tourist photography during family holidays, Haldrup and Larsen (2003) suggest that 'family gaze' is concerned with the 'extraordinary ordinariness' of intimate 'socialworlds', and this is a helpful lens through which to unpack the surface appearance of a simple 'family holiday to the beach'. Waterscapes are highly valued as both every-day and touristic spaces. The growing field of wellness tourism and indeed health geographies have shown the positive emotional, physical and psychological impacts of engagement with the coast. A growing body of work is beginning to show (White et al, 2013, Bell et al, 2015, Kelly, 2018) that many humans place high emotional value on coastal places and experiences, for themselves, their families and their psychological- as well as physical, wellbeing.

Tourism has long since recognised the importance of various blue spaces, and many have gained long-standing reputations for healing, spirituality and emotional wellbeing, including 'sacred' springs, holy wells, and coastal areas. Blue spaces are environments defined by the presence of water and include inland and coastal aquatic environments (Volker and Kistemann, 2011). These have been described in previous studies as 'therapeutic landscapes'; landscapes where the physical and built environments, social conditions and human perceptions combine to produce an atmosphere which is conducive to healing (Gesler,1992, Kaplan, 1995). Some research focuses on quantitative reviews of bluespace and wellbeing (Gascon et al, 2017), whilst others assess more intangible concepts of the relationship between place and happiness (Brereton et al, 2008). Key considerations asked in this paper are, 'what does being close to the sea mean to families on holiday and how does it make them feel?' 
Bell et al (2015) present useful work on coastal therapeutic landscapes and examine the various dimensions involved in costal activities and experiences. Their model seeks to advance understanding of how and why coastal spaces are experienced as therapeutic by looking at the overlaps between blue space, health and wellbeing. This research has shown that some humans prioritise opportunities to use the coast to progress towards personal goals('achieving' experiences), such as running, walking or other sports related action, others value opportunities to lose themselves ('immersive' experiences) or to connect with others ('social' experiences) (Bell et al, 2015). Several participants in another study of coastal wellbeing in SW England valued experiences of immersive restoration at the coast, (Kaplan, 1995). Restoration has been widely studied in the context of green space exposure but only recently in relation to blue space (Brereton et al, 2008). Evidence is emerging also that bluespaces can be particularly beneficial for psychological wellbeing (White et al 2013). This suggests that positive emotional connections may possibly be more likely in places that make humans (individuals or families) feel better.

Feelings of wellbeing near bluespaces can also be discussed through wider narratives of place, meaning and values. Place attachment can be described as an emotional bond or positive connection between an individual and a particular place. It is often further divided into sub categories; - 'place identity', where a place has symbolic importance as a repository for emotions and relationships that give meaning to human life, and 'place dependence', which refers to how places provide the conditions that facilitate peoples' goals in life (Beery and Wolf-Watz, 2014). The coast therefore, symbolises important place attachment, through its potential role in the co-construction of family authenticity and positive emotions, and through facilitating the key personal 
goals of 'a good family life', and 'quality time' (Snyder, 2007); albeit through the limited temporality of holidays.

The beach/seaside itself however, whilst idealized in tourism marketing (Law et al 2007), is often a far more complex place in reality. Over time, social constructions of the beach as a place to be, to avoid or to have fun, have changed considerably. Baerenholdt et al (2004) evaluate this changing landscape and review the historical contextualization of the beach as 'a place in process'. And although not the focus of this work, the seaside can in many places in the UK, host an array of socio-economic problems, far from the Instagram scenes of holiday company social media platforms. Even assessing the beach as a common chosen site for holidays, variable users can occupy the same spaces - each performing their own needs and connections in very different ways.

Obrador-Pons (2003) also advocates the beneficial insights to be gained by articulating tourism as a particular way of being in the world, a particular way of living, of participating in the world. The most immediate and practical way in which we are involved in, or occupy the world is through the body. Lived space, experiences, social practices knowledge and feelings are always corporeal and sensual (Edensor, 2000; Obrador-Pons, 2003, Edensor, 2007) - and this is central when assessing family bodies at or in the coastal water. Embodiment is not a key focus of this paper, but its presence is implicitly acknowledged as contributory context.

\section{A Conceptual Framework}

Whilst 'families on holiday' are an often taken for granted tourism segment, as we have seen, they are far from simple when attempting to understand how their emotional 
interrelationships, social reproductive roles and constructs of authentic identity are performed.

This primary research presented in the following sections explores

- emotional connections between family members as they partake in coastal tourism - emotional connections with the coast itself

- constructs of authenticity (existential and interpersonal) through performances of family tourism

- how the above help to create memorable tourism experiences that therefore reinforce potentially positive emotional connections and family bonding

- engagement with coastal spaces themselves as a form of connection

Figure 1, below offers a framework for exploration.

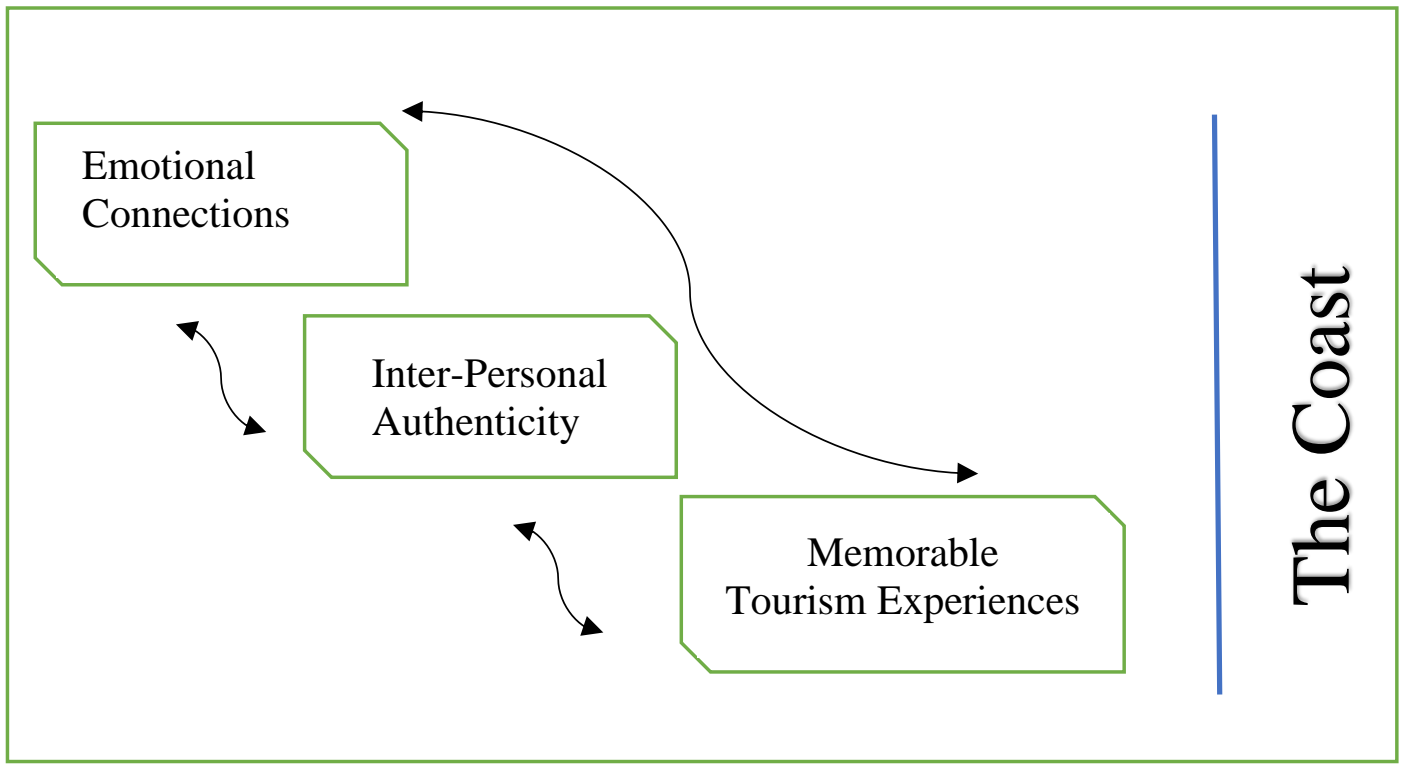

Figure 1. Family Tourism at the Sea: an exploratory framework

(Source: author)

This framework links concepts from the literature, with interview themes in the qualitative methodologies employed for this coastal case study. 


\section{Methods}

This research used the locus of the coast for its data collection, and the family as a unit of investigation, through which to meet its objectives. The coast in question was that bounded by the city of Brighton and Hove, on the Sussex south coast of England. Families were approached on the beach itself, whilst walking along the seafront promenade, and via a 'stop and chat about the sea' point set up at a traditional wooden beach hut.

Bachelard's phenomenological methodologies are key in this research, whereby we remain with the vital details of particular experiences or images in order to allow readers to imagine the experiences, that is, to live, embody them (Bachelard, 1969, cited in Game and Metcalf, 2011). Where possible, therefore, the words and feelings of the respondents are described and contextualised without excessive re-interpretation. The grouping of the family, the spaces of the coastline-beach-sea, and temporality of the present (that day) and past (other coastal holidays) constitute the 'who, where, when' aspects of investigation. Semi-structured interviews covered the key issues reflected in the research objectives and literature review. Deviations and the voice of the respondents were respected where certain topics incited animation and transgressions.

Semi structured interviews were used to ask family groups about a variety of issues including-

- their visit (duration, family composition, origin, motivations, activities engaged with)

- the emotional values such experiences held for family members

- emotions and emotional connections felt on the holiday 
- how their coastal holiday made them feel in relation to their own identity as a family.

- differential experiences of their trip within the family

- $\quad$ the spaces engaged with

- $\quad$ their coastal experiences (expectations, motivations, feelings, bodies, activities and wellbeing)

- past important family holidays by the sea

- what makes a family visit to the sea a memorable experience

Interviews took between 15 and 25 minutes each to conduct. The work is conceptually framed by theories and ideas discussed earlier, in relation to emotions, familial authenticity, memorable tourism experiences, and emotional-coastal connections.

Sixty interviews in total were achieved, divulging a wealth of qualitative responses. A variety of day trippers, weekend and longer-duration holiday visitors from the UK and abroad took part. Interviews were carried out over a 5-month period from June to September 2018, and across weekdays and weekends. Within a family grouping, the mother primarily responded in $70 \%$ of interviews (female voice), the father in $10 \%$ (male voice) and a mixture of both parents with interjections from other relatives (grandparents, aunts, and children- 'extended family or child voices') in the remaining $20 \%$. It is acknowledged that the maternal voice is dominant in the sample responses as a result. Children were not sought out specifically to answer interview questions, but sometimes involuntarily 'chipped in' with soundbites. Permissions and ethical considerations were adhered to throughout the process.

Attempts were made to ensure a varied demographic of responses (male/female, origin and so on) during interviews, but often, given the fluid nature of the outdoor 
environment, especially for interviews held on the beach - one adult needed to watch over the children during an interview. Poria and Timothy (2014) pose the question 'where are all the children in tourism research?', and this research includes their voice where it arose (-although future work would be very valuable if focusing on children's perspectives only!). Of the 60 families, 32 were from south east England, 15 were from outside the UK (Germany, France and Holland), and the remining 13 were from the immediate local area. Therefore 45 families, or $75 \%$ of respondents were British. This is important in that cultural differences exist in how the coast is experienced. The beach is performed differently in many parts of the world, in terms of weather responses, clothing, and phenomenological practices (playing games, making sandcastles, fishing, surfing, swimming, paddling). Therefore, no universal claims are made in this work about definitive family behaviours at the coast.

In addition, the spatial uniqueness and complexity of the chosen case study site, Brighton and Hove - is recognised here (Shields, 1990). Brighton has a long history of coastal tourism. The health tourists of the 17/1800s arrived following Richard Russell's work on the value of saltwater. The city has a colourful, raffish reputation (Shields, 1990) and was famous in the 1960s for mods and rocker encounters and clashes. In the current climate its coastline is a heterogenous space associated with gay tourism, London day-trippers, young urban weekenders, cultural tourists seeking out Regency architecture, and family tourism. There is no reduction therefore of Brighton beach to classify it as being a particular 'type of beach', - rather, the focus here is on one category of user, the family tourist.

\section{Results and Discussion}


Findings are presented thematically in the next sections. Respondent voices lead the narrative in keeping with the qualitative nature of this work. The two objectives of the paper - to explore emotional connections, and constructs of authenticity in family coastal tourism - form the structure of the analysis that follows. The nature of memorable tourism experiences and the role of the coast itself are contributory, additional narratives that emerged strongly in the interviews. The boundaries between these themes are somewhat arbitrary in that the interviewees themselves leapt between themes of feelings, family experiences, the sea, the beach and memories in an often-ad hoc manner. Their voices show interesting insights to how family tourism is experienced, felt and performed.

\section{Emotional Connections by the Sea}

Respondents were asked about emotions in a number of ways - what emotional value they placed on family holidays, what emotions they felt on the holiday, and how emotionally connected they felt to each other. Interestingly, the idea of emotions that emerged in the interviews displayed a temporal element and can be classified as (i) anticipatory emotions, (ii) embodied/present emotions, and (iii) reflective emotions. Holidays are key moments in family life, where expectations and emotions are high. This theme emerged in all the research interviews undertaken in Brighton and Hove. Work by Ashe (2012) shows that perception of emotional need-fulfilment is an important aspect of holiday decision making, and this is borne out by many responses in this study, feeding into the anticipatory emotions category noted above.

"when we book our holiday, just the thought of it keeps me going, for months sometimes. It's something to look forward to, where we can just switch off and be together" (respondent mother xxxi) 
Other, London daytrip visitors relished the thought of a Sunday visit to sea, as a way to get through the busy working week in the city.

“I've been thinking of this moment all week when I've been squashed on the underground. It's kept me going. Coming out of the train station in Brighton and just catching your first glimpse of that sea. You can almost feel the cold water on your feet before you even get to the beach".

Hedonic wellbeing, or 'an increased emotional state of happiness', was a strong self-reported outcome in this work $-100 \%$ of the sample expressed positive emotions or feelings when asked how it felt to be by the sea. These were almost all expressed in terms of present moment/embodied emotions - during the interview itself. Figure 2 below shows the most commonly expressed terms and emotions in relation to a question on 'how being at the sea makes you feel'. The emotions expressed are primarily positive and include multiple mentions of 'happy', ‘joy', 'together', 'fun', 'relaxed', and 'family'.

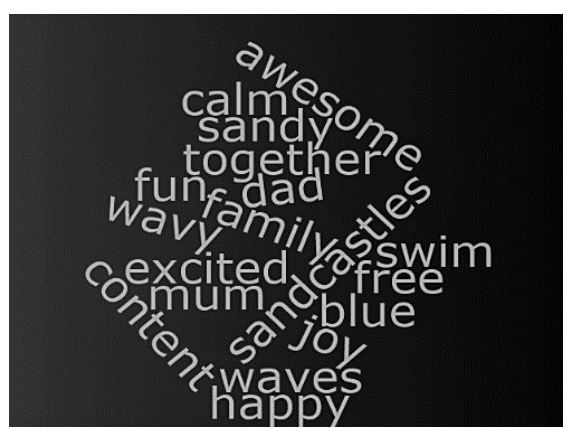

\section{Figure 2. WordCloud: Emotions and the Sea}

(Source: author)

Interestingly, these expressed emotions link back to Snyder's (2007) work on parental constructs of quality time. Her key focus is on what constitutes quality family time, but an interesting perspective here is where quality time takes places. For many respondents, enjoyable quality family time takes places outside the home, and for some, 
has temporal connotations, which is reinforced in the findings with references to 'Sunday afternoons' or 'on holiday'. These are times when visits to the sea usually take place. Snyder usefully refers to quality time classifications such as recreation (quality time as break from everyday life), bonding (quality time as an emotional connection), active leisure quality time (where family members are interacting and physically active) or place-based quality time (e.g. away from home).

These ideas reinforce the interviewee responses to the question on emotional values and family holidays by the sea. There was a sense of importance for many respondents - not just a frivolity, but a need - to carve out this time together. Bonding, connection, and doing things together are mentioned many times by respondents.

One dad noted that 'it's often too hectic to be that nice to each other during the week. There is a lot of shouting, hurrying and organising in our life. Getting everyone to where they need to be, on time. Its nice to come down here and have time to feel good, and enjoy ourselves and not to worry about all that for a bit'. Therefore, emotional connections may improve, as the holiday and the coastal space allow more relaxed interactions to take place.

\section{Family Identities, Existential and Interpersonal Authenticity}

An important aspect of this research centred on the relationship between family holidays and authenticity. Theories of psychological wellbeing, call upon people to live in accordance with their true self (Ong, 2009), although as discussed earlier, this is an often-contested concept (Goffman, 2007). The idea of existential authenticity as a psychological phenomenon (Kirillova and Lehto, 2015) is central to family tourism in so far as respondents themselves voice the desire 'to feel like a real family'. Perhaps one of the factors that allows families on holiday to construct or differentiate the idea of 
'authentic selves or existential authenticity' are the notions of presence, connection and (even accidental) mindfulness.

When tourists feel fully connected to the world, these moments can have a profound effect on them (Hom Cary, 2004). Such 'mindful authenticity' is a real outcome of much sea-based family tourism - in the moment, connected to the water, nature, and each other. It is both a simple and yet profound experience, as this research has shown.

" being here by the sea, makes you feel alive, and when you are in there, in the waves, with the kids, you can't think about anything else - your commute, the work project, you are just catching the next wave, seeing if you can stand on it, laughing when you fall in"

(respondent father, $\mathrm{xxxx}$ )

And, "When we are all here, I really see my kids - notice them, you know? I appreciate them all over again. Just playing, covered in ice-cream or whatever, being themselves. And I look at my husband and remember how lucky we are to have them, and each other I suppose. This is what it's all about, isn't it?" (mother, vii)

The 2 interview themes centring around 'how respondents' coastal holidays made them feel in relation to their own identity as a family', and 'differential experiences of their trip within the family' yielded interesting results. Kim and Jamal (2007) discussion of Inter-Personal Authenticity (IPA), noted earlier, involves emotional bonds, intimacy in family relationships and the pleasure derived from connections. IPA emerged as an important framework in this research where three key themes recurred amongst respondents- 'who we are as a family', 'who I am as a parent', and 'what my kids' childhood means to me', all emerged as recurring respondent 
themes. These aspects of inter-personal authenticity are reflective, perhaps of Day et al's (1995) notions of shared family paradigms. These self-constructs of idealised authentic roles and interplays are interesting at a family level.

Trips to the sea (regardless of length, interestingly) symbolized togetherness and a chance to do things 'that matter' - again reinforcing Snyder's theories of quality time. Perhaps an additional construct could be offered here - the notion of 'real family time'. Many respondents alluded to the idea of being a real family, and also to quality time. Combining these elements into a notion of real family time allows temporality and authenticity to be co-aligned more strongly. Despite some sociological theories to the contrary, many parents did express this 'splitting' of self - their home/everyday self, and their holiday/better-parent self. Perhaps this is facilitated by time, open space, fresh air, water, scope for fun and relaxation? This is not an unproblematic construct if it is examined more closely. It is also fair to say that not all family members experience this scope for relaxation and bonding equally.

Again, Obrador's work (2012) on the idealization of 'the family' on holiday is useful here. Everyday conflicts over labour sharing at home were for some, softened on holiday ('he can help me more on holiday because he isn't at work'), but for others they were reinforced and led to discontent for mothers ('it's the same old story, I just do everything', as one revealed). Many fathers said they enjoyed having time to spend with their children, playing and just 'hanging out'. Some mothers noted that their partners chose the more fun options on holiday, such as playing with the children in the water, or making sandcastles, while they were left to repeatedly organise snacks, bags, and sort out wet swimsuits and towels. As noted earlier, assessing how social reproductive roles change (or do not) while on holiday is of interest here, albeit in a limited sense of 
interplay at the coast itself. Gendered power relationships are complex and where they came up in conversation (not all respondents talked about them), they varied greatly. There is certainly scope for more research on this issue.

Questions were asked about inter-family (mother and father) roles, expectations and feelings around coastal holidays. It emerged that $80 \%$ of mothers in this survey has organised, booked and planned the trip/holiday to the beach. They expressed feelings of knowing what their children enjoyed best, but also took into account factors such as ease of access, cleanliness, safety, and nearby services, such as food, toilets, or additional play activities. Mundane tasks such as applying sunscreen, and handing out water bottles were largely maternal actions (observed and noted during interviews). Indeed, Obrador Pons (2203) observes that the most relevant embodied practices through which we become tourists are everyday, and ordinary. This is particularly true of family tourism where children's home routines, and preferences are often replicated on holiday, especially for very young children. Mothers overwhelmingly prioritised the needs and preferences of their children, beyond their own needs.

"So long as they are having fun, in the water, on the beach, that's the main thing really. These are their childhood memories we are making, I've had mine, so it's their time now." (respondent mother, vii) This sentiment above further reinforces authenticity in terms perhaps, of the idea of 'real childhoods'. There is the implied notion, however idealized, of the simplicity of a seaside trip, as the essence of childhood. The parent and the grandparent are instrumental in their family roles as providers of authentic childhood experiences. Concurrently, the sea acts as co-creator in this experience-process.

Feelings of contentment were high when children were happy, although some expressed feelings of frustration at the replication of domestic gendered roles on holiday 
There was also conflict over who 'deserved' a break most, in some instances, and the subtleties of paid versus hidden domestic labour emerged for some respondents

"I work all week, so it's nice to get down here and relax and do nothing" (dad, xi) - followed by his wife's reply (mother, xxvii): “So you think I don't work all week? I wonder who looks after the children and keeps the house going then? Or who organised this trip, packed this picnic, this sunscreen, these buckets and spades?!"

Another mother noted on a very similar theme, "I do everything on holiday, same as at home - I packed everything, got us sorted at the hotel, organise all the beach stuff, dry and change the kids after being in the sea, sort out their wet things when we get back. It's not much of a rest really, just a different background". Yet, there seemed to be a resigned acceptance of these inequalities, offered up in the name of positive quality time for the whole family, particularly the children.

"Yes, it's not much of a rest for me really, but you do it for them - and spending family time together here is more important than us arguing over who's doing what".

As mentioned earlier however, many interviews took place with mainly one adult, as the other parent watched over the children on the open space of the beach/in the water - so these conversational exchanges might have been more plentiful in a more contained environment where both parents were interviewed together. The intention was however, to capture the in-situ response to the space itself, informally, on the beach, and within the reality of the family grouping as it presented itself.

These gendered power relations are also emotional...Pocock (2015), suggests that while tourism involves physical travel, it does not always concurrently involve emotional travel - our domestic emotional states around caring from children, parenting 
and inter-parent conflict may well be carried with us as we holiday. Buda and McIntosh (2012) similarly note that emotions travel with us, and through us. Mothers who did the majority of childcare at home, seemed to replicate this on holiday, and also displayed more emotions of worry - so while the sea was seen as a largely positive presence, for some it meant a safety hazard in terms of water, and strangers. 'My kids are still small, so you have to go with them to the shore, and you have to keep looking, or they might wander off with someone, you can't be too careful', one mother noted. Therefore, family coastal holidays can be complicated emotional encounters, where predicted idealisms of loving, bonded experiences are sought out, but sometimes are diluted by the continuation of everyday family labour roles and interactions. The coastal holiday does arguably however, allow for and facilitate the potential for suspension of some everyday problems and stresses and improved emotional connections.

The interviews explored the kinds of activities and experiences the families had on their seaside trip and how they felt about them. Bondi and Davidson (2003) advocate that encounters are not given, rather, they are produced by the experience of the agents involved. These intricacies of children and parental interplay, and performative experiences in coastal spaces were explored.

“there's more freedom at the beach, isn't there? I mean, yes, you have to keep an eye on them in the water for sure, but they're just happy in there. I don't have to keep shouting at them not to get wet or dirty, because that's the point really, isn't it? Let them be kids...they don't get much of a chance to do that anymore with all that's on. When they come down to the sea, they can just be kids again, even the big ones."

(respondent mother, xi) 
Positive psycho-social wellbeing seemed to emerge through family-coastal encounters. Emotions run high for family tourism experiences, they matter - and they have huge symbolic meaning that forms intricate narratives of family identities, values and family histories.' We look forward to our holidays every year, it keeps us going', said one mother, 'especially in the winter, when you are all cooped up together indoors, you can imagine yourself there on the beach, or you can look back on last year's photographs - Facebook is great for that, the reminders'.

Interview transcripts dealing with positive emotional responses were content analysed and then classified into psychological and social categories.

Table 1 loosely categorizes responses to questions about how family holidays/trips to the sea affected them (emotions/connections/wellbeing). Phrases such as 'It's great to rest and relax', 'it's so good for my headspace', 'coming down here is like a family mental health boost!' and 'its' just lovely to be together, we can connect with each other again' - were simplified and classified below.

Table 1. Classification of Responses/Descriptor Benefits

(Source: Author)

\begin{tabular}{|l|l|}
\hline Psychological & Social \\
\hline mental health & togetherness \\
\hline brain/head & family (\& 'being' a family) \\
\hline stress & bonding \\
\hline downtime/time out & quality time \\
\hline rest/a break & the children being children \\
\hline relaxation & connecting \\
\hline clarity & sharing, enjoying \\
\hline
\end{tabular}

Across the sample the most often quoted responses to how coastal holidays made families feel, were, interestingly, the social wellbeing aspects of togetherness, 
connection and family (supporting Snyder, 2007); and the psychological aspects of rest, a break from the everyday and relaxation by the sea. Authenticity descriptors such as 'children being children', and 'time to be a family' were also commonly cited. These ideas of 'real family time' and 'authentic childhoods' are reinforced once more. Mental wellbeing and stress release were important perceived psychological wellbeing outcomes among the sample. Blue mind concepts and the work of White et al (2010) and Nichols (2018) resonates strongly with these findings, supporting the importance of emotional, social and psychological connections at and with the sea. There is no doubt that place shapes the health of visitors (Andrews and Kearns, 2005), and here it does so in a myriad of ways, some subtle, some explicit and visible.

What is more complex to ascertain in the research, is the differential importance placed on the holiday itself (any holiday?), the togetherness of the family trip, and the coastal setting itself (which the research above shows does improve wellbeing) across different family groups. More work is needed on this. In summary, an important outcome of this research shows that authenticity is a key factor in coastal family holidays - in terms of the collective self-identifying unit of 'the family', parental roles within the family, and the construction of 'real childhood experiences'. Existential authenticity or 'real familiness' is afforded a temporary and temporal opportunity in seaside holiday performances.

\section{Coastal Spaces}

Although presented as a separate category here, in reality the sea, the beach and the water were mentioned in most of the held discussions, regardless of the question asked. Positive emotions associated with bluespace emerged as a strong theme in the interviews for this research, supporting Gelser’s (1992) ideas of ‘therapeutic landscapes', mentioned earlier. This research shows again that humans value the coast, 
and especially the water itself, as a fluid form of subjective wellbeing. It may even enable them to feel better, and connect better with each other, due to reduced stress levels, and the performance of 'quality time'. Bell et al's (2015) work, mentioned earlier, is also useful in framing the findings of these interviews. Emotional attachments to the coast they argue, can develop through the accumulation of diverse individual and/or shared coastal experiences. The shared coastal experience is pertinent to family tourism in particular and is seen in these findings.

"We all just feel better when we come down to the sea; there is no question about not getting in, never mind the weather. Just the feel of the cold water hitting your skin, hearing the kids shriek, splashing, swimming, - there is nothing to beat it really. It makes us all feel happy, and we get along better with each other." (respondent mother xii)

Some parents did not get into the water themselves, but just enjoyed the chance to sit on the beach and watch their children, or to gaze at the sea itself. Contemplative and aesthetic experiences also therefore contributed to bluespace wellbeing. This restorative immersion in seascapes and spaces (both reported by respondents and observed by the researcher) supports Kaplan's (1995) ideas on restoration, where stress is reduced by the presence of/engagement with nature, or in this case, coastal bluespace.

"I just sit here on the beach, looking out. Honestly, that is all I need. With all the hustle and bustle of our week at home, afterschool clubs, work, and the house, I never get to just sit and do nothing. The sea lets you do that, it's just there."

(respondent mother xiv) 
Thompson (2007) compares such looking out to sea with encountering infinity, or at least, a world beyond oneself. The quietness of a pause, to look without purpose, is restorative and healing.

For other families, using the water in motion, for kinetic movement sports such as windsurfing, bodyboarding, surfing or stand-up-paddleboarding (SUP) was key. This partaking in physical activities is an important aspect of overall emotional connection and quality family time (Snyder's active leisure classification) - and the sea can provide a natural and inviting participative space.

"We bought a SUP board this summer. It's great because we can all fit on it, and it makes you get in the water, just to use it. I'm trying to increase my distances, all the way to pier and back, each time I go in. You soon feel it in your arms and legs. It's amazing, just out there far from shore, very quiet too" (respondent father, iii) Fathers who were interviewed were most likely to talk about physical activities on the water, and to assess whether the water conditions were 'right' for certain activities such as paddleboarding or bodyboarding. Bleakley (2016) suggests that the material environment affords a kind of sensuality that constructs a potential identity as a keen observer of wave shapes, winds and currents. There was evidence of this role of performing custodianship - and enacting adventuresome and teaching roles; how to get on the board, when to paddle, how to catch a wave, which connected adult with child in an affective way, bodies without interface in the water itself.

The results showed the type of spaces engaged with by respondents, and revealed a classification of usage by the respondents that elicited different experiences and emotions. There appeared to be somewhat of a continuum of emotional response related to the sea, the beach, or the coast more generally - and also the geographical 'prepositions of place' became important in our analysis as 'near', 'next to', and 'in', 
the sea, also generated different emotions. This requires further attention in future work as it was an unexpected but interesting finding. For some respondents it was all about being in the sea, for others (notably the European families) - being next to ('the very cold British sea) water was enough. Grandparents were often parked on benches nearby on the promenade, overlooking things, particularly where steep beach shingle slopes made for unsteady ground.

In addition, the space of the body itself, was the starting point for feelings generated in tourism encounters. Our first, most immediate and intimately felt geography is the body, the site of emotional experience and expression (Davidson and Milligan, 2004, cited in Buda et al, 2014). The body, immersed in cold British seawater, certainly elicited enthusiastic responses.

'I can't wait to get myself in the sea! As soon as we get to the beach, I just take everything off, and run in! Even if it's freezing cold at first, I don't care. It's so exciting!' (respondent child, ii)

'It's sooooo cold, I can't feel my fingers or toes, but I don't care - it's brilliant!' (respondent child, i)

This intertwining of body and beach and sea is fluid and typical in tourism encounters. The body itself is spatial, it creates places by means of uniting us directly with people, spaces, and things-and it is not distinct from the environment in which it dwells (Obrador-Pons, 2003). This is particularly true when bodies inhabit the sea or ocean body and marine aquatic space as mutually defining.

Figure 3, below collates content mentioned by respondents at different spatial scales to reflect their own descriptions of the coast, the water and their bodies at the seaside. ('how would you describe this beach, the sea, and yourself, here today?') 


\section{Scale}

\begin{tabular}{|l|l|l|}
\hline \multicolumn{1}{|c|}{ COAST (near/next to) } & \multicolumn{1}{|c|}{ WATER (in) } & \multicolumn{1}{|c|}{ BODY/EMOTION } \\
\hline $\begin{array}{l}\text { Crowded, quiet, busy, } \\
\text { empty, open, long, } \\
\text { secluded, services }\end{array}$ & $\begin{array}{l}\text { Wavy, calm, bouncy, } \\
\text { crashing, strong, flat, cold, } \\
\text { fresh, warm, salty }\end{array}$ & $\begin{array}{l}\text { Body: exposed, covered, } \\
\text { flabby, fit, free, pale, } \\
\text { tanned, unfit, goosebumps, } \\
\text { cold, warm }\end{array}$ \\
\hline $\begin{array}{l}\text { Stony, sandy, pebbly, } \\
\text { slopey, flat, warm, windy, } \\
\text { cold, breezy }\end{array}$ & $\begin{array}{l}\text { Clear, murky, blue, green, } \\
\text { translucent }\end{array}$ & $\begin{array}{l}\text { Emotions: Invigorated, } \\
\text { free, joyful, carefree, } \\
\text { childlike, alive, happy, } \\
\text { myself, content, calm }\end{array}$ \\
\hline
\end{tabular}

Figure 3. Content Analysis of External/Internal Descriptors of Coastal and Emotions. (Source: Author)

The emotive spatialities of proximity to or immersion in the sea showed the clear interrelationship between space and body, the material and emotional. Many described the human conditions of the beach, according to how many others were there (busy, or quiet), whilst also describing the physical conditions of the coast or beach (pebbly, sandy, the weather that day). Descriptions of the water blurred with emotive responses, facial expressions and voices rose and fell when asked to describe the water and how it felt to be in the sea. Children sometimes butted in to parental interviews here, excitedly describing how they used their bodies to jump or catch waves, to swim underwater, getting knocked down, swallowing water and so on. Colours, and how the water itself was acting or behaving that day were important in held conversations. Bodies were often described self- judgementally (by mothers), or in relation to temperature - but in complete contrast, the emotions expressed were overwhelmingly positive (invigorated, free), see Figure 3. This interplay between space and human response emerged strongly 
throughout, supporting d'Hauteserre's (2015) call for reintroducing corporeality and the role of emotion into accounts of tourism realities. She notes, rightly, that the notion of embodied (or corporeal and emotional) performative engagement produces more nuanced understandings of tourists' experiences and allows one to look at the role of all participants in the co-creation of behaviours and practices in the tourist zone.

"we love it when we can all go in the sea, we can jump and shout, and get wet or sandy, and nobody minds. It's so fun, the best thing ever" (respondent child, iv).

Obrador-Pons (2007) also refers to this sensuality of bodily engagement with the beach and the sea - and the importance of touch. 'Letting the sun get in, feeling the coolness of the water on the skin and playing with sticky textures of the sand are some of the main delights that people find on the beach - touch holds the key to bringing back life, sensation and enjoyment to the beach' (p.138). Children in particular found joy in this sensory release of touch, liberated from clothes and everyday spatial enclosures. Emotional expressions of joy and contentment, - hedonic wellbeing, peppered all of the interviews held. These overlap with terms expressed in Figure 2 earlier. "I just love it here, it makes me happy, pure and simple" (respondent grandmother i) "you can just switch off when you come down to the sea, it just comes in and goes out, up and down the beach, no matter what we do. There's peace in that"

$$
\text { (respondent mother viii) }
$$

The theme of existential authenticity also arises in these narratives of sea and identity. 'I come home to myself a bit when we are here by the water', one mother noted. These themes were expressed throughout many of the interviews, and speak to the strong socio-psychological potential of place, bonding and sea connections. The sea, it can be 
argued, is very much a co-agent in constituting and structuring these family emotional experiences on holiday.

\section{Memorable Tourism Experiences}

A final coming together perhaps of all the aforementioned themes, can be found in the expression of memorable tourism experiences. To feel joy, freedom and connection and to later reflect on those feelings through recall, shared stories, photographs and videos create important points of reference for family milestones. MTEs- Memorable Tourism Experiences (Kim et al 2012), are central in the story of any family (Tung and Ritchie, 2011), and here, emotional connections, quality time, constructs of authenticity, the coast and the water are central actors in these stories.

Nichols (2012) notes that some of our best memories were formed near the water, in the water - with our friends and our loved ones, 'my brain', he says, 'is full of water memories, and they form who I am'. These ideas of self-identity link to place-identity and lived space, an affective attunement that is fluid and yet firm.

“I can't imagine us going on any holiday that isn't by the sea. It's what we do, and what we have always done," (respondent mother, iii) The expression of 'it's what we do', emphasises once again the idea of familial existential authenticity - and the shared family paradigm. Self-identifying as a 'coastal holiday family' reinforces the collective memorable tourism experience. Place is important here and interviewees often referred to other seaside holidays whilst speaking. The tendency to nostalgiacize past holidays is also part of this creation of memories. 'Do you remember when' was a phrase often interjected throughout the interview processes. Anecdotes and shared memories of past holidays help to reinforce 
feelings of existential familial authenticity. An important nuance, might be to note that such personal memories do not necessarily symbolise 'what all/real families do', rather what 'our family' did. Meaning and authenticity are therefore constructed within, to some extent, when examined through the temporal lens of the remembered past.

Strong emotional connections to landscape have been built up across multiple generations, and are reinforced by personal experiences (Collins, and Kearns, 2010). In over $50 \%$ of the British interviewees, respondents had been taken to Brighton on family holidays as children themselves, so the idea of legacy and continued family traditions was strongly evident. Continuity and legacy therefore also serve to reinforce the notion of familial authenticity. Strong family identities can be expressed and shared when grandparents, for example, participate in holiday-making.

Obrador (2012) also observes the importance of the family holiday in 'homemaking practice'. The home and domestic realm, are connected to the holiday and the beach, through the vessel of the family. Tourism, it is noted, does not always have to be about escaping home, it can also be about making home, through different forms of displacement. The family, at the beach, still need to eat, to play and interact, look after their children, help them dress, supervise their safety and many other normative domestic actions. The proximity of the sea and sunshine can potentially elevate the mundane to the joyful, excited and possible. The ritual of return visits reinforces the legacy of the family holiday practice.

"my nan used to bring us down here from London when I was a lad, I took my son, and now we come here with the grandchildren, its changed lots since my day, but its lovely" (respondent grandfather, ii) 
Irvine (2007) notes that certain spaces are more prone to produce certain kinds of emotions than others - and this was shown to be true of the coast. The love of the sea (or indeed fear of the sea) is a social construction, often conveyed through the medium of the family, performed in leisure time and space. Many parents conversationally referred to the idea of showing their children the beaches, coves and seaside towns they had been to as children themselves. Others valued the passing on of coastal skills of their own, teaching their children to surf, to fish, to collect mussels, or go crabbing. So, memory-making was performed through both place-meaning and recreational performances.

Regardless of specific family roles, it was clear that a love of coastal space expressed here is a key element of childhood experiences, Game and Metcalf (2011), suggest our chronological past, and particularly our maternal connections, influence our current enjoyment of meaningful spaces. The beach is for many -symbolically, a place of childhood freedom, fun and excitement. 'It's got to be the seaside, every time surely?' declared one grandmother, 'it's got everything for the nippers, and all free, nothing like it is there?' As discussed earlier, a key parental motivation for choosing family holiday experiences is the aim of creating these positive childhood experiences, and these in turn become identifying family memories. Togetherness and memorymaking are key drivers according to Gram, (2005), while Servidio and Ruffalo (2016) assert that emotional involvement is a critical aspect of memorable and lasting tourism experiences. Sthapit and Coudounaris' (2018) work has shown, similar to this research - that measurements of memorable tourism experiences are strongly correlated with meaningfulness and happiness (eudomonic and hedonic wellbeing). Authentic family encounters by the sea, as explored in this research - support all of this-emotional 
bonding, meaningful 'real' quality time together, contentment, and an affinity to the sea space itself are in fact, the cornerstones of these findings.

\section{Conclusion - Beyond 'A Day at the Seaside' in Tourism and Leisure Narratives}

So, what can be said of all these experiences, these emotions and the coastal spaces that allow them to flow? This exploratory research has reviewed aspects of connection, family, emotions, bodies, authenticity and coastal spaces. All overlap to create a fluidity of experience, of dynamic, socio-spatial emotions. The importance of narrative must not be overlooked in tourism studies- who we are, what we enjoy, what this place, this trip, this beach, this water -makes us feel like, what it means to us individually or as a family, and how we remember it, are core issues for deepening our understanding of the human condition of tourism. Humans are in essence, emotions and thoughts contained in corporeal spaces, albeit affected by a myriad of external social constructs but our quest for connection with other significant humans in our lives, and with nature itself are core existential conditions. They are not secondary to other aspects of tourism behaviour, rather, they inform, filter and differentially affect our experiences in time and space.

This work aimed to explore the emotions and experiences related to coastal tourism encounters in one UK site, and it has shown the largely positive, joyful expressions of its respondents. A diverse set of experiences were reported within specific spatial contexts of the coast, the beach and the water itself. Thick dialogue, rich descriptions and animated performances brought the importance of this coastscape to the forefront of real and imagined family stories, memories and legacies. The paper also discussed family narratives and emotional experiences in the context of coastal tourism. It has shown that these spaces can ameliorate or indeed sometimes replicate family 
dynamics in many cases - where mundane domestic issues either become suspended and improved, or for others, simply transposed. For some respondents, there was a continuation of the private rhythms of the family, into the outdoor, temporal, public, beach setting. Idealized projections of family inter-personal authenticity were unpacked and discussed. For many families, the notion of 'being a real or proper family' was expressed, often through the construction of 'quality time' encounters. Performing parenting roles that fed into socially constructed notions of 'good mothers and fathers', connecting to their children in fun and/or meaningful ways was highly valued. Gender and power relationships around social reproduction issues were expressed by many. For some parents, a seaside holiday represented a break from the mundane chores of 'home'; for others it meant 'more of the same'. For many families however, the beach holiday epitomised idealized space and time, a place for quality time, bonding, relaxation and togetherness, without the distractions characterised by everyday places. As a result, psychosocial wellbeing increased across all interviewees - and the effect of these interconnected emotions, spaces and the water itself, made almost everyone feel better.

Memorable tourism experiences are important in the story of most families. These experiences are emotional and emotive. They are often strengthened by the connections that are enabled in the spatial setting of the coast, the beach, the water. Quality time is critical in family tourism practices, but constructed differentially within various parenting styles and values. The connection between the concepts of 'time' (quality, temporary, or suspended) and tourism, warrants more attention.

Meaning, emotions and existentialism all need to be considered in more depth within the tourism academy, given that tourism is an important dimension in how we 
conduct and perform our family lives. These issues are indeed beyond 'a trip to the seaside', they are the components that help to shape family identities. Families 'doing family' as a particular configuration of human connection is an important aspect of all tourism performances. How tourists imagine and perform 'familiness' in the context of coastal tourism is complex, as this paper has shown, but warrants deeper research. Future research needs to delve deep inside the feelings evoked by tourism spaces and their associated social connections. More tourism studies need to be conducted on families and emotions and on the voice of children and their experiences of family holidays (especially new forms of families - single parent, blended step-families, homosexual parent families, bereaved families and more). More work is also needed on the interaction and gendered power relationships between parents as they perform family holidays. In the realms of the coastal, more succinct questioning is needed on the geography of coastal prepositions - the differential experiences felt beside or in the sea itself. Perhaps there is scope for a more central acknowledgement of the sea space itself within themes of emotion, authenticity and connectivity. To conclude on this note, citing Nichols (2012): 'when we are staring at the sea, watching it, it takes away our stress, it reduces our anxiety, it connects us to ourselves. When we go to the sea, we connect to ourselves, at the edge of the water. When we go to the ocean with friends, with our families, we form these deep, blue, memories that become who we are- that connect us with the people we love, in the places we love.' A fitting synopsis perhaps, of the emotional value of family holidays by the sea. 


\section{References}

Ahmed, S. (2004) Collective feelings: or, the Impressions Left by Others. Theory, Culture and Society 21. pp 25-42.

Andrews, G.J. and Kearns, R.A. (2005) Everyday Health Histories and the Making of Place: The Case of an English Coastal Town. Social Science and Medicine 60, pp26972713.

Ashe, J. (2012) Understanding Feelings Can Help Hotels Improve Guest Experiences. Loughborough Echo, 3.

Bachelard, G. (1969) The Poetics of Space. Beacon Press: Boston.

Baerenholdt, J', Haldrup, M., Larsen, J. and Urry, J. (2004) Performing Tourist Places. Taylor and Francis: Aldershot.

Beery, TH and Wolf-Watz, D. (2014) Nature to place: Rethinking the environmental connectedness perspective. Journal of Environmental Psychology, 40. 198-205.

Belhasson, Y. and Caton, K. (2006) Authenticity Matters. Annals of Tourism Research Volume 33, Issue 3, pp. 853-856

Bell, S.L., Phoenix, C., Lovell, R. and Wheeler, B.W.(2015)Seeking Everyday Wellbeing: The Coast As A Therapeutic Landscape. Social Science and Medicine 142. $56-67$

Brereton, F., Clinch, JP. And Ferreira, S. (2008) Happiness, Geography and the Environment. Ecological Economics, vol. 65, issue 2, 386-396

Buda, D. and MacIntosh, A. (2012) Hospitality, Peace and Conflict: Doing 'fieldwork' in Palestine. The Journal of Tourism and Peace Research 2(2) 50-61 
Buda, D., d' Hautessere, AM., and Johnstone, L. (2014) Feelings and Tourism Studies. Annals of Tourism Research 46. pp102-114.

Buda, D.M. (2015) Affective Tourism; Dark Routes in Conflict. Routledge: Abingdon.

Brown, S.D and Tucker, I. (2010) Eff the Ineffable: Affect, Somatic Management and Mental Health Service Users, In: Gregg, M. and Seigworth, G.J. (2010) The Affect Theory Reader. Duke University Press: N.Carolina.

Collins, D. and Kearns, R. ( 2010) 'It's a Gestalt Experience' - Landscape values and Development Pressure in Hawkes Bay, New Zealand. Geoforum 41, pp 435-46.

d'Hauteserre, AM (2009) L'altérité et le tourisme : construction du soi et d'une identité sociale. Espace, populations, Sociétés. pp 279-291.

d'Hauteserre, AM. (2015) Affect Theory and the Attractivity of Destinations. Annals of Tourism 55. Pp 77-89.

Davidson, J and Milligan, C. (2004) Embodying Emotion: Sensing Space: Introducing Emotional Geographies. Social and Cultural Geograohy, 5(4). pp. 523-32, cited in Buda, D., d' Hautessere, AM., and Johnstone, L. (2014) Feelings and Tourism Studies. Annals of Tourism Research 46. pp102-114.

Day, R., Gilbert, K., Settles, B. and Burr, W. (eds) Research and Theory in Family Science. Pacific Grove, CA: Brooks-Cole

Edensor, T. (2000) Staging tourism: tourists as performers. Annals of Tourism Research. 27 (2). pp 322-344,

Edensor, T. (2007) Mundane mobilities, performances and spaces of tourism, Social \& Cultural Geography, 8:2, 199-215, DOI: 10.1080/14649360701360089 
Game, A. and Metcalf, A. (2011) 'My Corner of the World' : Bachelard and Bondi Beach. Emotion Space and Society 4, pp. 42-50.

Gascon, M. et al (2017) Outdoor Blue Spaces, Human Health and Wellbeing: A Systematic Review of Quantitative Studies. International Journal of Hygiene and Environmental Health Volume 220, Issue 8, November 2017, Pages 1207-1221

Gesler, W. (1992). Therapeutic Landscapes: Medical Issues In The Light of the New Cultural Geography. Soc. Sci. Med. 34, 735-746.

Goffman, E; (1990) The Presentation of the Self in Everyday Life. Penguin Books: London and New York.

Gram, M. (2005) Family Holidays. A Qualitative Analysis of Family Holiday Experiences, Scandinavian Journal of Hospitality and Tourism, 5(1), pp. 2-22

Gregg, M. and Seigworth, G.J. (2010) The Affect Theory Reader. Duke University Press: N.Carolina.

Haldrup, M., \& Larsen, J. (2003). The Family Gaze. Tourist Studies, 3(1), 23-46.

Hom Cary, S. (2004)The Tourist Moments. Annals of Tourism Research 31 (1), pp 6177.

Kaplan, S.,(1995). The Restorative Benefits of Nature: Toward An Integrative Framework. J. Environ. Psychology. 15, 169-182

Kearns, R. and Collins, D. (2012) Feeling for the Coast: the Place of Emotion in the Resistance to Residential Development. Social and Cultural Geography, 13(8). Pp. 937955 
Kelly, C and Smith, M. (2009) Holistic Tourism: Integrating Body Mind and Spirit. Chapter In: Sheldon, P. \&Bushell, R. (eds) Wellness Tourism: Mind, Body, Spirit, Place. Innovation and Tourism Book Series: Cognizant, USA.

Kelly, C (2010) Analysing Wellness Tourism Provision: A Retreat Operators' Study. Journal of Hospitality and Tourism Management 17(1) pp 108-116

Kelly, C. (2012) Wellness Tourism: Retreat Visitor Motivations and Experiences Tourism Recreation Research. Volume 37(3) pp 205-213

Kelly, C (2018) 'I Need the Sea and the Sea Needs Me' - Symbiotic Policy Narratives for Sustainability and Wellbeing. Journal of Marine Policy. Vol 97.November 2018, Pages 223-231 https://doi.org/10.1016/j.marpol.2018.03.023

Kim, H. and Jamal, T. (2007) Touristic Quest for Existential Authenticity. Annals of Tourism Research 34(1), pp181-201.

Kim, JH., Brent Ritchie, J.R., and McCormick, B. (2010) Development of a Scale to Measure Memorable Tourism Experiences. Journal of Travel Research 51 (1) pp 12-25

Kirillova, K. and Lehto, X. (2015) An Existential Conceptualization of the Vacation Cycle. Annals of Tourism Research Vol: 55, pp110-123.

Law, L., Bunnell, T., \& Ong, C.-E. (2007). The Beach, the gaze and film tourism. Tourist Studies, 7(2), 141-164.

Lewis, T. (2018) The Big Chill: the Health Benefits of Swimming in Ice Water. The Guardian. Dec 23. Accessed March 2019.

https://www.theguardian.com/global/2018/dec/23/the-big-chill-the-health-benefits-of$\underline{\text { swimming-in-ice-water }}$

Minnaert, L and Jens (2017) Family Travel Survey. Family Travel Association. NYU School of Professional Studies. Online report : Accessed February 2019. 
file:///C:/Users/User/AppData/Local/Packages/Microsoft.MicrosoftEdge_8wekyb3d8bb we/TempState/Downloads/P1718-0036-2017_Family_Travel_Survey\%20(3).pdf

Nicols, W.J (2012) Exploring our Blue Mind. TedX Talk, San Diego. Online:

https://www.youtube.com/watch?v=7n95yIBq6jo. Accessed February, 2019.

Nichols, W.J. (2018) Blue Mind: How Water Makes you Happier, More Connected and Better at What you Do. Abacus: London.

Obrador-Pons, P. (2003) Being-on-Holiday: Tourist Dwelling, Bodies and Space. Tourist Studies 3(1). Pp 47-66.

Obrador-Pons, P. (2007) A haptic geography of the beach: naked bodies, vision and touch, Social \& Cultural Geography, 8:1, 123-141, DOI: 10.1080/14649360701251866

Obrador-Pons, P. (2009) Building Castles in the Sand: Repositioning Touch on the Beach, The Senses and Society, 4 (2), pp. 195-210, DOI: 10.2752/174589309X425139

Obrador, P. (2012) The place of the family in tourism research: Domesticity and thick sociality by the pool, Annals of Tourism Research, 39(1), pp. 401-420.

Ong, A. (2009) On the measurement and mismeasurement of happiness: Contemporary theories and methodological directions. In: A. Dutt, B. Rudcliff (Eds.), Happiness, economics, and politics: Towards a multi-disciplinary approach, Edward Elgar Publishing: Northampton. , pp. 33-44

Pocock, N. (2015) Emotional Entanglements in Tourism Research. Annals of Tourism Research 53. Pp 31-45

Poria, Y and Timothy, D.J. (2014) Where are the children in tourism research?, Annals of Tourism Research, Vol 47. pp 93-95, 
Prtichard, A, . Morgan, N. and Ateljevic, I (2011) Hopeful tourism: A New Transformative Perspective. Annals of Tourism Research 38 (3), pp. 941-963

Seabirds, Brighton (2019) Seabirds Blog. Available at https://seabirdsdotblog.wordpress.com/. Accessed March 2019.

Servidio, R. and Ruffalo, I. (2016) Exploring the Relationship between Emotions and Memorable Tourism Experiences through Narratives. Tourism Management Perspectives 20 (2016) pp151-160.

Shaw, SM (2010) Diversity and Ideology: Changes in Canadian Family Life and Implications for Leisure. World Leisure Journal 52(1) pp 4-13

Schanzel, H.A. and Yeoman,I. ( 2014) The Future of Family Tourism, Tourism Recreation Research, 39:3, pp.343-360

Shields, R. (1990) The 'System of Pleasure': Liminality and the Carnivalesque at Brighton. Theory, Culture and Society (7), pp. 39-72.

Smith, M and Puckzo, L. Editors. (2016) The Routledge Handbook of Health Tourism. Routledge: London.

Snyder, K.A. (2007) A Vocabulary of Motives: Understanding How Parents Define Quality Time. Journal of Marriage and Family, 69 (May) pp 320-340.

Tung, VWS. and Ritchie, JRB. ( 2011) Exploring the Essences of Memorable Tourism Experiences. Annals of Tourism Research 38, 1367-1386.

Volker, S., Kistemann, T., (2011). The impact of blue space on human health and wellbeing and salutogenic health effects of inland surface waters: a review. International Journal of Hygiene and Environmental Health 214, 449-460. 
Wang, N. (1999) Rethinking Authenticity in Tourism Experience. Annals of Tourism Research 26(2) pp. 349-370

White, M., Smith, A., Humphryes, K., Pahl, S., Snelling, D., Depledge, M., (2010). Bluespace: The Importance Of Water For Preference, Affect, And Restorativeness Ratings Of Natural And Built Scenes. J. Environmental Psychology. 30, 482-493.

White, M.P., Pahl, S., Ashbullby, K., Herbert, S., Depledge, M.H., (2013). Feelings of Restoration from Recent Nature Visits. Journal of Environmental Psychology.35, 40-51. 